\title{
Dimensional Analysis of Parameters Affecting the Flow Discharge Coefficient in Duckbill Spillways with Presence of Guide Vanes and Investigating Results in Laboratory Conditions
}

\author{
Seyedeh Zahra Hosseini-Teshnizi ${ }^{1}$, Manouchehr Heidarpour ${ }^{1}$, Seyed Saeid Eslamian ${ }^{1}$ \\ Kaveh Ostad-Ali-Askari ${ }^{2 *}$ \\ ${ }^{1}$ Department of Water Engineering, Agricultural College, Isfahan University of Technology, Isfahan, Iran \\ ${ }^{2 *}$ Department of Civil Engineering, Isfahan (Khorasgan) Branch, Islamic Azad University, Isfahan, Iran \\ koa.askari@khuisf.ac.ir
}

\begin{abstract}
The changes in the height of the head water in duckbill spillways in different discharges due to the increase of the crest length, is more limited. Flow discharge coefficient in duckbill spillways is a function of the total head water, spillway height, wall thickness, shape and type of the crest and angle of the side walls with flow direction. Using dimensional analysis and providing dimensional variables enables that factor affecting the behavior and duckbill spillway relations with presence of guide vanes are fully investigated. In this study, using a dimensional analysis, a relation was found between the flow discharge coefficient in the duckbill spillways with the presence of guide vanes. The results of the theory with laboratory conditions were also examined. The tested model is a triangular duckbill spillway with apex angle of $45^{\circ}$. The crest of spillway has smooth edge. The width of the guide vanes was considered as a coefficient of the length of one side of the duckbill spillway with a height equal to the spillway height. According to the results, the range of the flow coefficient for the duckbill spillway is greater than the straight spillway, which shows that changing the water depth the flow discharge coefficient in the duckbill spillway is greater than the flow discharge coefficient in the straight spillway. The ratio of the length of one cycle of spillway to the water depth, the ratio of the height of the spillway to the water depth, the Froude number, the ratio of the spillway width to the waterdepth, the ratio of the guide vane width to the water depth, the number of guide vanes and the location of deployment can be influenced in the flow discharge coefficient in the duckbill spillway with flow guide vanes.
\end{abstract}

Keywords: Dimensional analysis, Flow Discharge Coefficient, Flow Guide Vane, Sharp Crested Spillway, Theoretical Principles

\section{INTRODUCTION}

Sharp-crested spillways are used in numerous cases in the channel as perpendicular spillway along the channel width or shrink, long-crestedspillwayor side spillway[1]. Fig. 1 shows the pattern of flow and the vertical cross section of the flow profile along the central axis, which is obtained using theoretical principles and observations in the laboratory. According to the Fig. 1, the flow phenomena over the spillway is a three dimensional flow. Researchers have considered the flow one-dimensional to achieve a practical result, [2].

According to Fig. 1 the flow direction over the duckbill spillways has not vertical line on the crest edge and passed under the oblique line of the crest edge. In the upstream and downstream areas, the flow direction is more parallel to the symmetry axis than the perpendicular direction to the crest and this phenomenon is more visible in the downstream nose where the flow is accumulated and overflowed. This causes to reduce the 
Dimensional Analysis of Parameters Affecting the Flow Discharge Coefficient in Duckbill Spillways with Presence of Guide Vanes and Investigating Results in Laboratory Conditions

efficiency of the spillways [3]. For this reason, the efficiency of the triangular duckbill spillways is greater than the trapezoidal duckbill spillways, with the constant of other factors affecting the flow. Since the angle of flow direction or velocity vector is closer to the vertical with the axis of symmetry of crest in the first type spillway relative to the second type spillway. The perpendicular velocity component will also be more to the crest axis, which, according to the continuity equation, flow will pass more $[2,4]$.

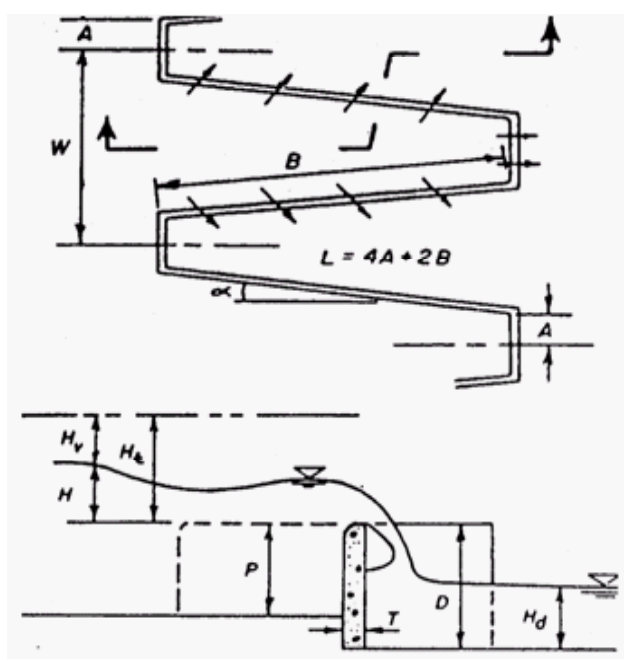

Fig1. The flow profile over the duckbill spillway and the factors influencing it

Duckbill spillways are long crested spillways that have restricted changes in water head with increase in the crestlengthin different flow discharges. Due to high performance of duckbill spillways in high flow discharge with constant water head, the need to investigate more about this type of spillways felt.

One of the weaknesses of the triangular duckbill spillways is the high interference of the flow in the area after the nose of the spillway. After passing through the spillway, the water hits the channel wall and interferes with the flow at the downstream of the spillway and this current interference reduces the velocity and energy loss and reduces the efficiency of the spillway [5].

According to the research of Amanian, Tullis et al. [6], water flow discharge of duckbill spillway is a function of total head water, effective spillway length and flow discharge coefficient. The discharge coefficient is a function of the total head water over the spillway, the spillway height, the wall thickness, the shape and type of the crest and the angle of the side walls with the flow direction. The equation that used to calculate the flow discharge over the duckbill spillways is based on the general equation of straight spillways:

$$
Q=\frac{2}{3} L C_{d} \sqrt{2 g}\left(H_{t}\right)^{3 / 2}
$$

Where $Q$ is the flow discharge $\left(\mathrm{m}^{3} / \mathrm{s}\right)$, g is the gravity acceleration $\left(9.81 \mathrm{~m} / \mathrm{s}^{2}\right), \mathrm{L}$ is the effective length of the spillway $(\mathrm{m})$ and $\mathrm{C}_{\mathrm{d}}$ is the flow discharge coefficient and $\mathrm{H}_{\mathrm{t}}$ is the total head water $(\mathrm{m})$ that obtained from the following equation:

$$
H_{t}=H+H_{V}
$$

Where $\mathrm{H}$ is the static head water $(\mathrm{m})$ and $\mathrm{H}_{\mathrm{v}}$ is the dynamic headwater $(\mathrm{m})$, that $\mathrm{H}_{\mathrm{v}}$ is obtained from the following equation:

$$
H_{V}=\frac{V_{0}^{2}}{2 g}
$$

Where $\mathrm{v}_{0}$ is the average upstream velocity $(\mathrm{m} / \mathrm{s})$, 
Dimensional Analysis of Parameters Affecting the Flow Discharge Coefficient in Duckbill Spillways with Presence of Guide Vanes and Investigating Results in Laboratory Conditions

In the using of tools to improve the hydraulic performance of spillways, many researchers achieved favorable results by performing experiments on oblique and duckbill spillways. Ansari studied oblique spillways with the use of guide plates (plates that installed perpendicular to the upstream of the spillway body) and diagonal plates (plates that are on the one side tangential to the bottom of channel and on the other side on the spillway crest) can be respectively about 15 and 20 percent increasesin the effective length of the spillway crest, resulting in increase in its flow discharge. In addition, in oblique spillways the guide vanes and diagonal plates increase 20 and 25 percent discharge coefficient, respectively [1]. In this research, the utilization of flow guide vanes with different arrangements has been investigated on the improvement of performance of duckbill spillway with apex angle of $45^{\circ}$.

\section{THEORY}

In a laboratory study on hydraulic structures in order to make the results of the experiments operational, it is necessary firstly, there must be a geometric similarity between the model and the prototype, and, secondly, there must be a dynamic similarity between the model and the prototype. Using dimensional analysis and providing dimensional variables enables the factors that affect the behavior and influences of spillway in the presence of flow guide vanes to be fully investigated.

Here, using a dimensional analysis, a relation is obtained for the flow discharge coefficient in the triangular duckbill spillways with presence of guide vanes. It should be noted that the force of gravity is the effective force of the flow with the free surface. Its origin is the acceleration of gravity. The forces of resistance against the force of gravity and reduce that effects are friction force of the wall, surface tension and viscosity. That the first one relates to the flow path characteristics, and the other two relate to fluid characteristics. In the present study, dimensional analysis was performed using the Buckingham Pi-theorem. According to this theorem, if a physical process involving $\mathrm{k}$ number of dimensional variable, it can be reduced in an equation with k-r number of independent dimensionless parameter. Where, $\mathrm{r}$ is the minimum number of necessary reference to state variables.

Considering a cycle of triangular duckbill spillway with the presence of guide vane in the plan, parameters affecting the flow discharge are considered as follows:

Q: flow discharge, L: effective length of the spillway, W: channel width equal to the spillway width (w), P:spillway height, $\rho$ : density of fluid, $S_{0}$ : longitudinal slope of the channel, $\mu$ : dynamics viscosity of fluid, g: gravity acceleration, $\mathrm{V}_{0}$ : fluid velocity in the upstream of the spillway, $\alpha$ : apex angle of triangular duckbill spillway, $\mathrm{Y}$ : upstream water depth, $\sigma$ : fluid surface tension, $\mathrm{L}_{\mathrm{v}}$ : width of the vane, $\mathrm{S}$ : location of deployment of guide vane and $\mathrm{N}$ : number of guide vane

Based on the results of previous studies, it has been observed that the number of cycles (n) used in duckbill spillways has no effect on the discharge coefficient and the flow discharge of each cycle. Therefore, this variable is not considered.

Using the Buckingham Pi-theorem, after combining and simplifying non-dimensional variables, the relation is obtained as follows:

$$
F_{2}\left(\frac{L}{Y}, \frac{P}{Y}, F r, \frac{W}{Y}, S_{0}, \alpha, W e, R e, \frac{Q}{V_{0} Y^{2}}, \frac{L_{V}}{Y}, N, S\right)=0
$$

Where $F r$ is upstream Froude number, Re is the Reynolds number and We is the Weber number. The flow over the duckbill spillway isn't laminar flow. The boundary layer has an ignorable thickness, so the effect of viscosity in fluid behavior can be ignored. Thus, the Reynolds number is eliminated from the above equation.

If the water level on the spillway was low, surface tension will affect the flow behavior. Considering that the restriction of minimum water level over the spillway was observed, surface tension could be neglected. In 
Dimensional Analysis of Parameters Affecting the Flow Discharge Coefficient in Duckbill Spillways with Presence of Guide Vanes and Investigating Results in Laboratory Conditions

this study, the minimum height of $3 \mathrm{~cm}$ over the spillway was considered. As a result, Weber number was also eliminated from the equation.

The effect of channel longitudinal slope and the apex angle $(\alpha)$ of the spillway were ignored due to be constant in all experiments. Considering the discharge coefficient $\left(C_{d}\right)$ as a parameter dependent on other dimensionless parameters and replacing it with the parameter $\mathrm{Q} /\left(\mathrm{V}_{0} \mathrm{Y}^{2}\right)$ can be rewritten as follows:

(5)

In the case of simple spillway, the five initial parameters mentioned above are effective.

\section{LABORATORY EQUIPMENT}

The experiments were carried out in a laboratory channel with length of 7, width of 0.32 and height of $0.35 \mathrm{~m}$. The proposed model is a triangular duckbill spillway with apex angle of $45^{\circ}$ that made of galvanized sheet with $1 \mathrm{~mm}$ thickness. The spillway threshold has smooth edge. The height of this model according to the channel width and the proposed relation $\mathrm{W} / \mathrm{P} \geq 2.5$ by Taylor [2], was considered $12 \mathrm{~cm}$ (in this relation, $\mathrm{W}$ is the channel width and $\mathrm{P}$ is the channel height). A straight spillway with a length equal to the width of this spillway was tested to calculate the equivalent flow discharge (Fig. 2).

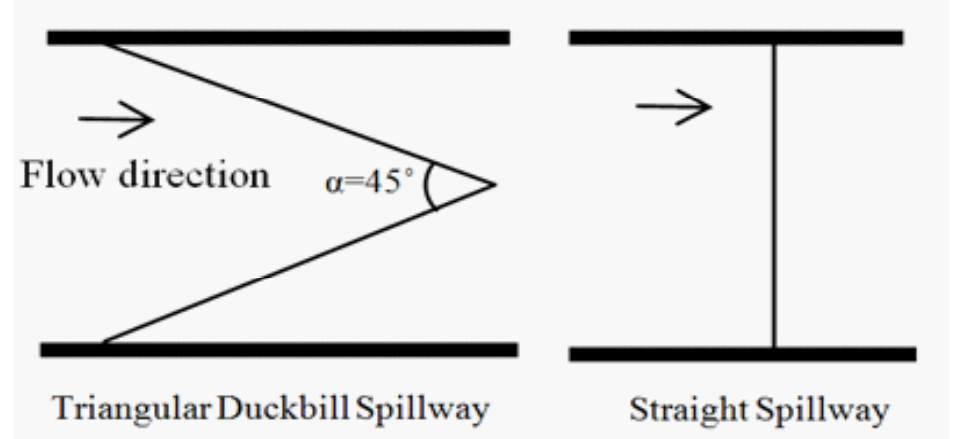

Fig2. The straight spillway and triangular duckbill spillway used in this study with apex angle of $45^{\circ}$

In the range of spillway location, the effects of flow input (the effect of viscosity and related secondary phenomena) must be completely eliminated, so that the velocity profile does not fluctuate. For this purpose, velocity profiles were obtained in the length and width of the channel and compared with each other. The model was located in $4.5 \mathrm{~m}$ from the beginning of the channel wherethe velocity profiles have similar process (Fig. 3 ).

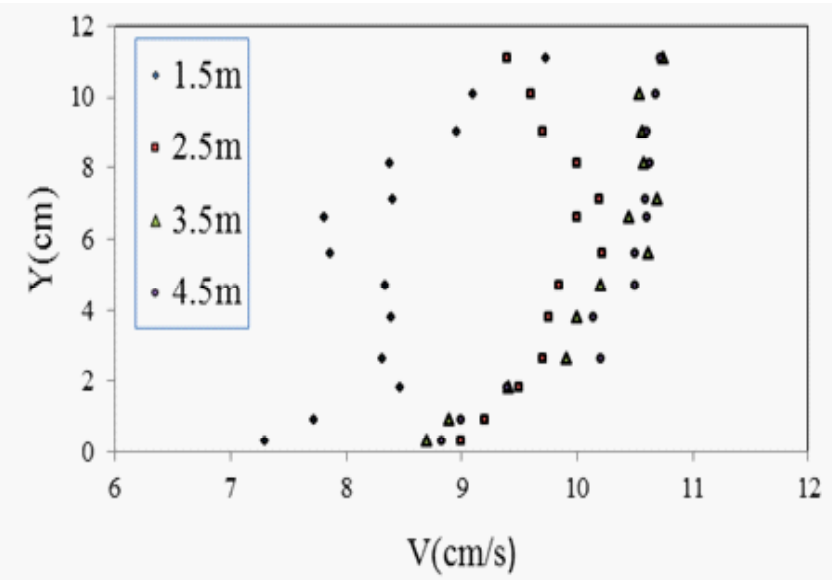

Fig3. Velocity profiles in 1.5, 2.5, 3.5 and 4.5m from the beginning of the channel in the central axis.

American Research Journal of Civil And Structural Engineering Page 4 
Dimensional Analysis of Parameters Affecting the Flow Discharge Coefficient in Duckbill Spillways with Presence of Guide Vanes and Investigating Results in Laboratory Conditions

All models were carried out for 4 flow discharge between 14 to 18 lit/s. The location of measuring the average velocity at the upstream of the spillway is the location of depth measurement. The width of the guide vanes was selected equal topercentage of length of one side of spillway $(2.5,5$ and 7.5 percent of length) respectively equal to 1,2 and $3 \mathrm{~cm}$.

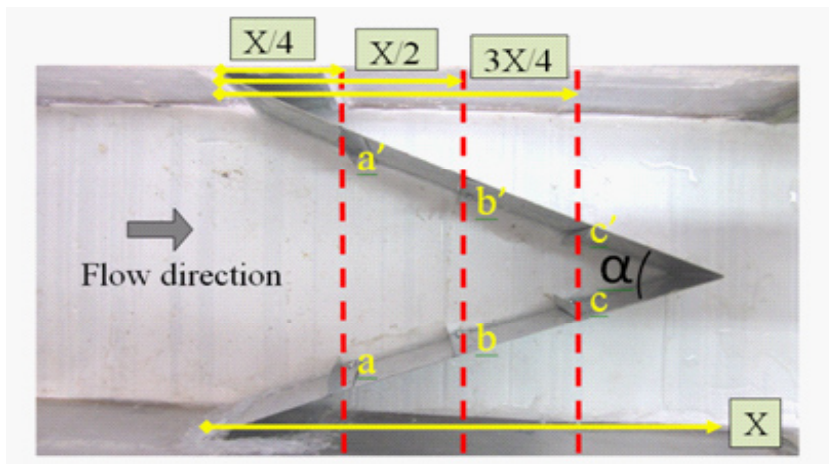

Fig4. The naming of location of the guide vanes in the spillway
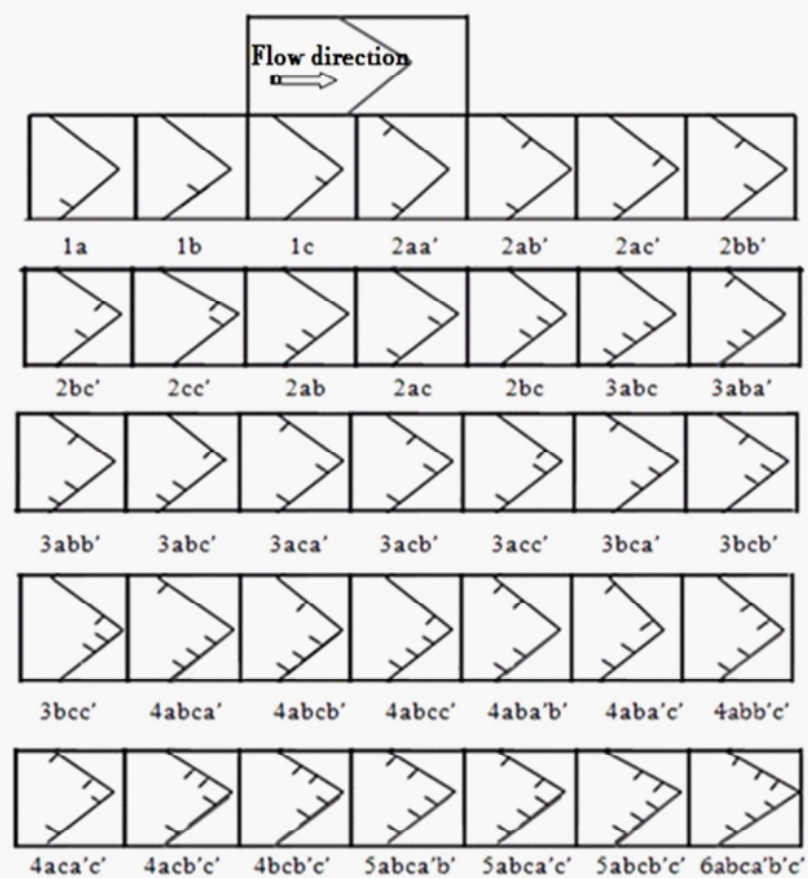

Fig5. Schematic design of different states of guide vane locations in the upstream of triangular duckbill spillway with apex angle of $45^{\circ}$

\section{ANALYSIS OF RESUltS}

\section{Relation between Discharge Coefficient $\left(C_{d}\right)$ and L / Y}

First, in Fig. 6, the variations in the discharge coefficient $\left(C_{d}\right)$ versus $L / Y$ are provided in the straight spillway and simple triangular duckbill spillway and its values are compared with each other. By comparing the changes, it can be said that, firstly, the $C_{d}$ for straight spillway is greater than the $C_{d}$ for triangular duckbill spillway. Secondly, the rate of change of $\mathrm{C}_{\mathrm{d}}$ for the triangular duckbill spillway is greater than the straight spillway which 
Dimensional Analysis of Parameters Affecting the Flow Discharge Coefficient in Duckbill Spillways with Presence of Guide Vanes and Investigating Results in Laboratory Conditions

shows that by changing the water depth, the changes of $C_{d}$ in triangular duckbill spillway are more than $C_{d}$ in the straight spillway.

It can be seen that in two spillways, by increasing the $\mathrm{L} / \mathrm{Y}$ ratio, the $\mathrm{C}_{\mathrm{d}}$ first increases and then decreases. In Fig. 7, a simple triangular duckbill spillway has been compared with models with guide vanes.

According to Fig. 7, the trend of changes in $C_{d}$ is similar with the change in L/Y ratio in all three groups. On the other hand, all of $C_{d}$ in group 1 are more than the other two groups and more than simple triangular duckbill spillway and show that the L/Y ratio can be an effective factor in changing the discharge coefficient. It can be concluded from Fig. 6 and Fig. 7 that in the high values of L/Y (i.e, in the amount of low water depth), the maximum value of the discharge coefficient will be obtained. This means that with increasing depth, the discharge coefficient decreases.

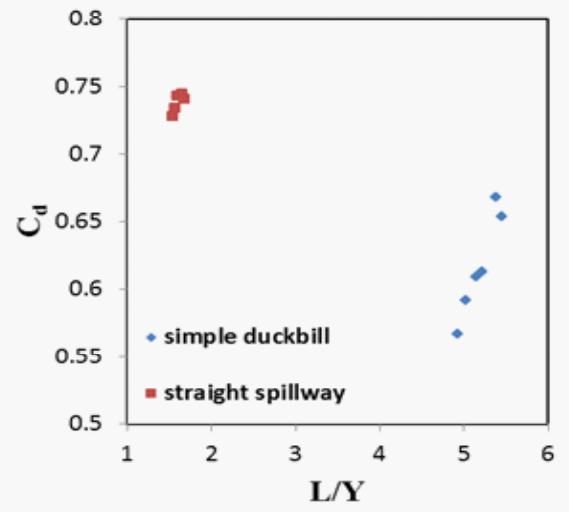

Fig6. Changes of $C d$ and $L / Y$ in simple triangular duckbill spillway compared to straight spillway
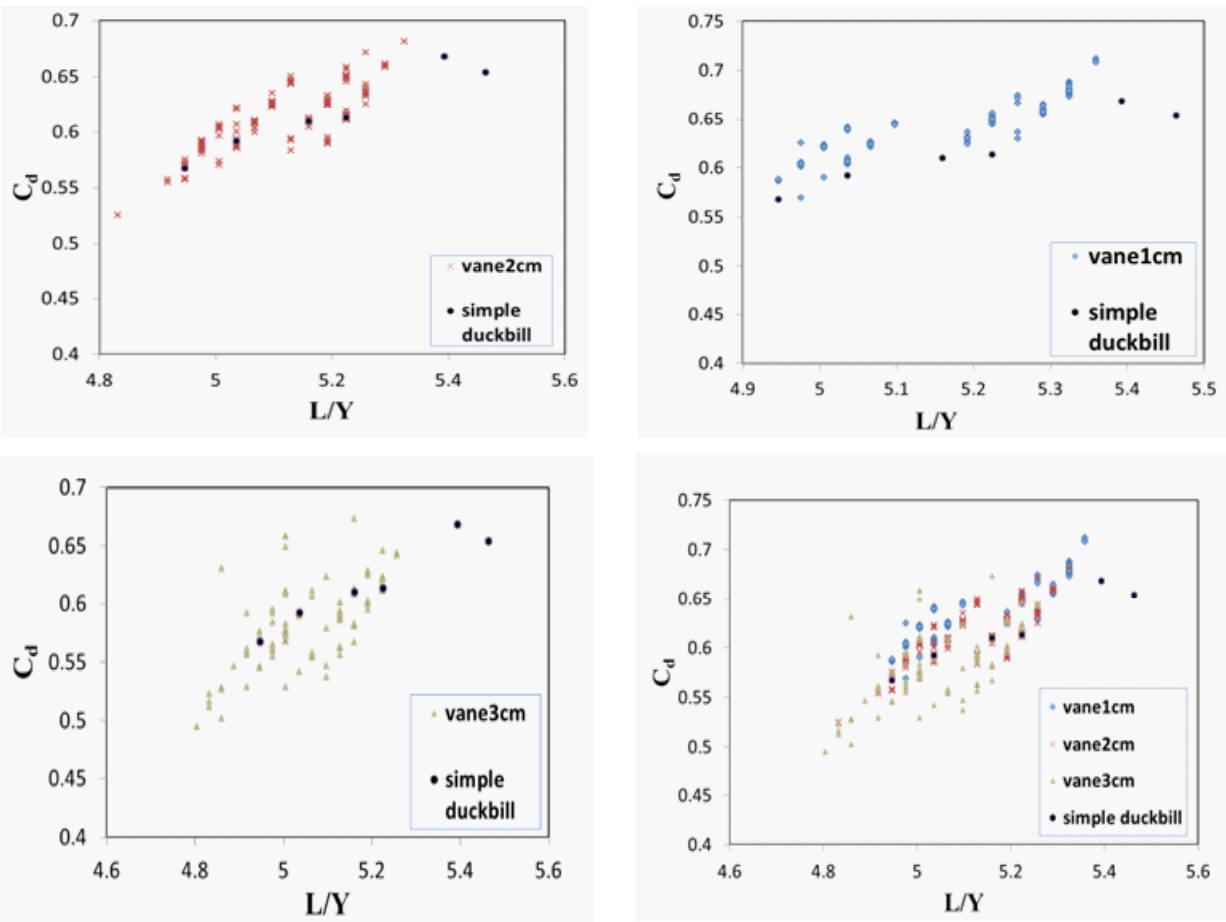

Fig7. Changes of $C d$ and $L / Y$ inmodels with guide vanes of 1, 2 and $3 \mathrm{~cm}$ width compared to simple triangular duckbill spillway 
Dimensional Analysis of Parameters Affecting the Flow Discharge Coefficient in Duckbill Spillways with Presence of Guide Vanes and Investigating Results in Laboratory Conditions

\section{Relation between Discharge Coefficient $\left(C_{d}\right)$ and $P / Y$}

First, in Fig. 8, the variations in the discharge coefficient $\left(\mathrm{C}_{\mathrm{d}}\right)$ versus $\mathrm{P} / \mathrm{Y}$ are provided in straight and simple triangular duckbill spillway and their values were compared. It can be said that in two spillways, increasing the $\mathrm{P} / \mathrm{Y}$ ratio (decreasing water depth), the discharge coefficient first increases and then decreases. In Fig. 9, a simple triangular duckbill spillway has been compared with models with guide vanes.

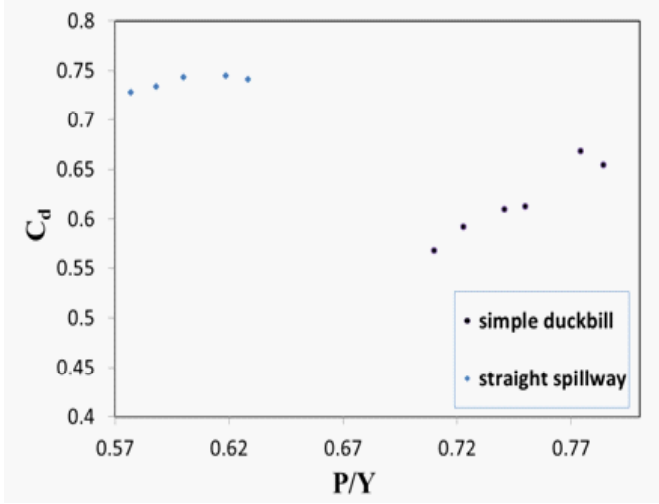

Fig8. Changes of $C_{d}$ and $P / Y$ in simple triangular duckbill spillway compared to straight spillway
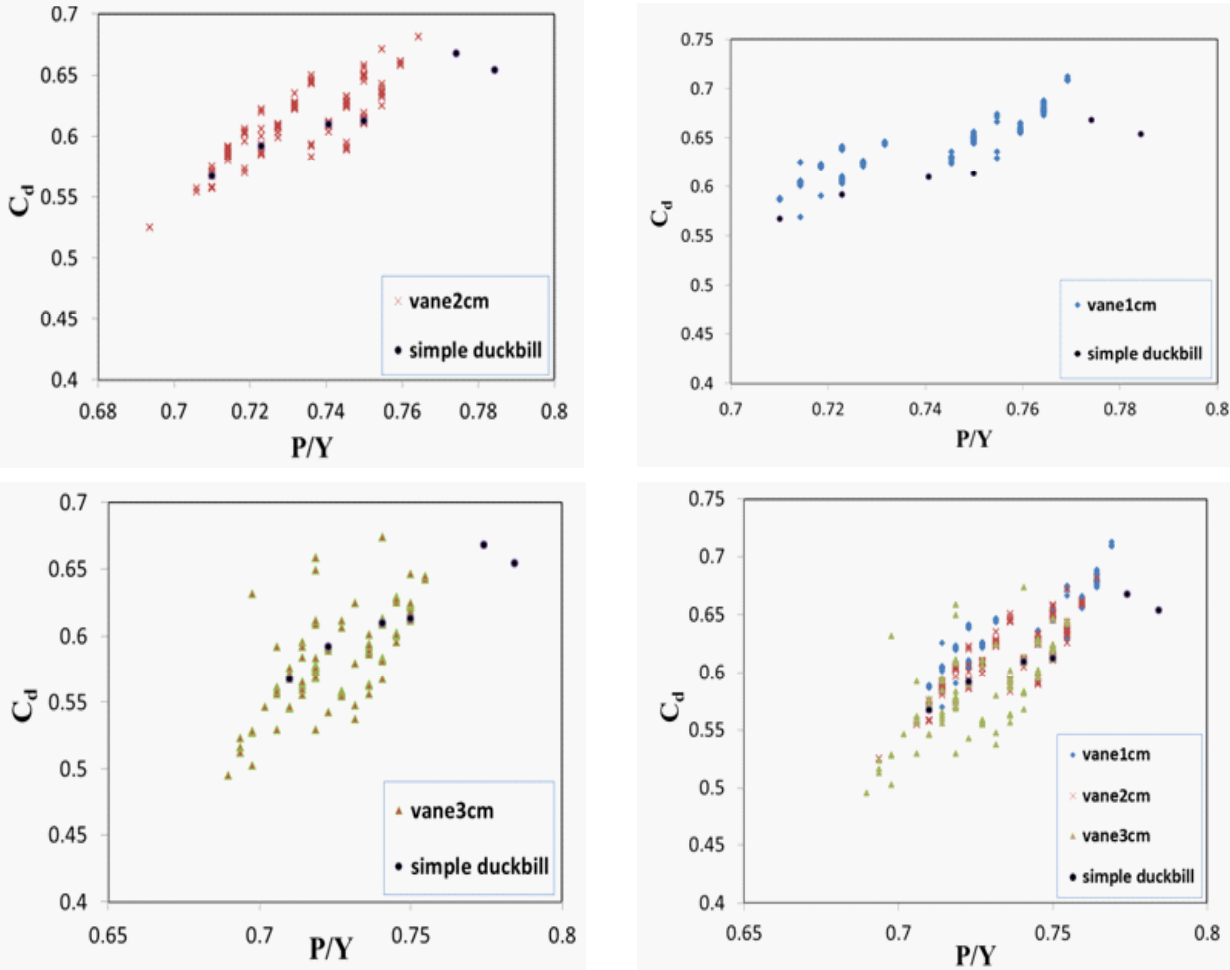

Fig9. Changes of $C_{d}$ and $P / Y$ inmodels with guide vanes of 1,2 and $3 \mathrm{~cm}$ width compared to simple triangular duckbill spillway

From Fig. 9, it was determined that the process of changing the flow coefficient $\left(\mathrm{C}_{\mathrm{d}}\right)$ by changing the $\mathrm{P} / \mathrm{Y}$ ratio is similar in all three groups. On the other hand, all of $\mathrm{C}_{\mathrm{d}}$ in group 1 are more than the other two groups and more than simple triangular duckbill spillway and show that the P/Y ratio can be an effective factor in changing the discharge coefficient. 
Dimensional Analysis of Parameters Affecting the Flow Discharge Coefficient in Duckbill Spillways with Presence of Guide Vanes and Investigating Results in Laboratory Conditions

\section{Relation between Discharge Coefficient $\left(\mathrm{C}_{\mathrm{d}}\right)$ and Froude Number $(\mathrm{Fr})$}

First, in Fig. 10, the variations in the discharge coefficient $\left(C_{d}\right)$ versus Froude number (Fr) are provided in a straight spillway and a simple triangular duckbill spillway, and its values are compared with each other. Then, in Fig. 11, a simple triangular duckbill spillway has been compared with models with guide vanes. It can be said that in all models the discharge coefficient $\left(\mathrm{C}_{\mathrm{d}}\right)$ decreases with increasing Froude number (Fr).

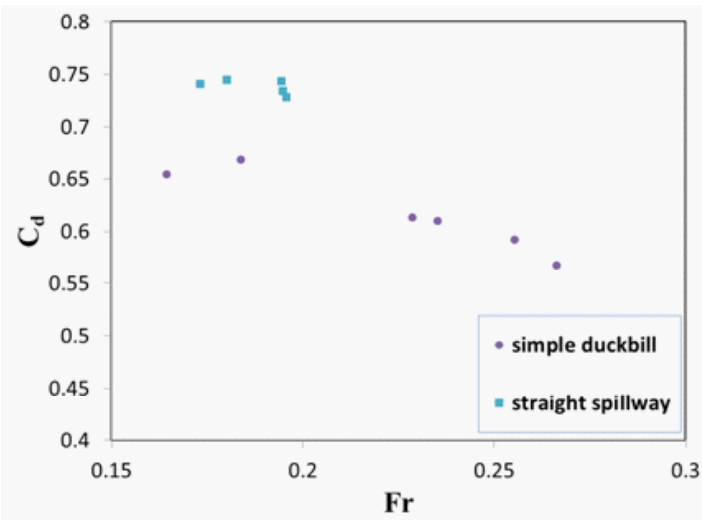

Fig10. Changes of Cd and Fr in simple triangular duckbill spillway compared to straight spillway

It is clear from Fig. 11 that the trend of changes in $C_{d}$ is similar with the change in the ratio of Froude number (Fr) in all three groups. On the other hand, all of $C_{d}$ in group1 are more than the other two groups and more than simple triangular duckbill spillway and show that the Froude number (Fr) ratio can be an effective factor in changing the discharge coefficient.
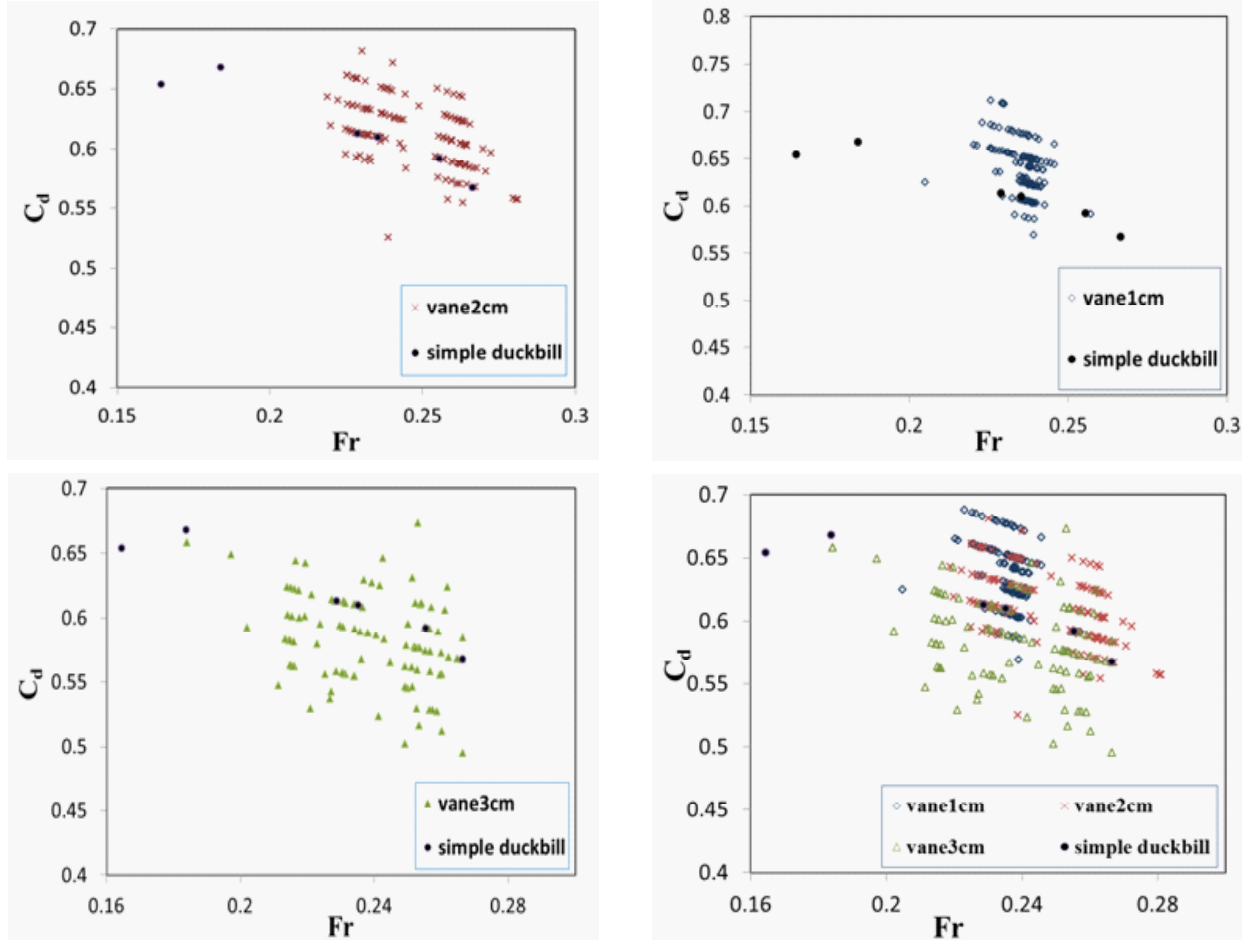

Fig11. Changes of Cd and Fr inmodels with guide vanes of 1, 2 and $3 \mathrm{~cm}$ width compared to simple triangular duckbill spillway 
Dimensional Analysis of Parameters Affecting the Flow Discharge Coefficient in Duckbill Spillways with Presence of Guide Vanes and Investigating Results in Laboratory Conditions

As the discharge increases, the velocity and the depth of flow increase, but according to the Froude number (Fr) formula $(\mathrm{Fr}=\mathrm{V} / \sqrt{\mathrm{gY}})$, the effect of velocity is more than the square root of depth, resulting in an increase in the Froude number. It follows from Fig. 10 and Fig. 11 that, as Froude number (Fr) increases, the amount of the $\mathrm{C}_{\mathrm{d}}$ decreases.

\section{Relation between Discharge Coefficient $\left(\mathrm{C}_{\mathrm{d}}\right)$ and W/Y}

First, in Fig. 12, the variations in the discharge coefficient $\left(\mathrm{C}_{\mathrm{d}}\right)$ versus $\mathrm{W} / \mathrm{Y}$ are provided in a straight spillway and a simple triangular duckbill spillway, and its values are compared with each other. It can be said that in two spillways, increasing the $\mathrm{W} / \mathrm{Y}$ ratio, the $\mathrm{C}_{\mathrm{d}}$ first increases and then decreases. Then, in Fig. 13, a simple triangular duckbill spillway has been compared with models with guide vanes. According to Fig. 13, the trend of variation of $\mathrm{C}_{\mathrm{d}}$ with the change in $\mathrm{W} / \mathrm{Y}$ ratio is similar in all three groups.

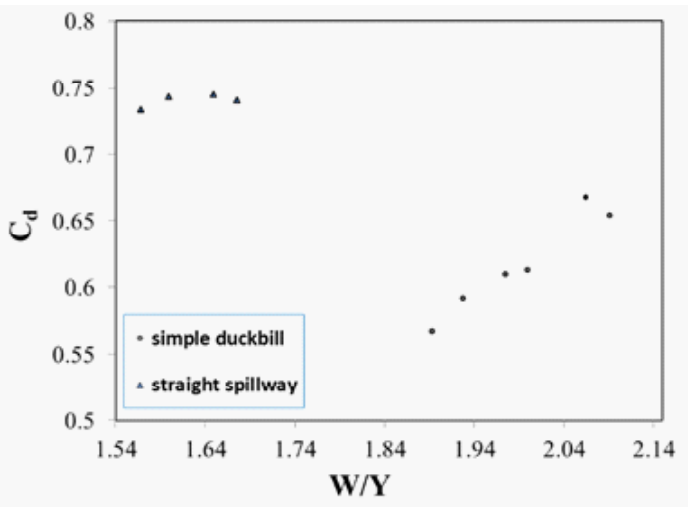

Fig12. Changes of $C d$ and $W / Y$ in simple triangular duckbill spillway compared to straight spillway
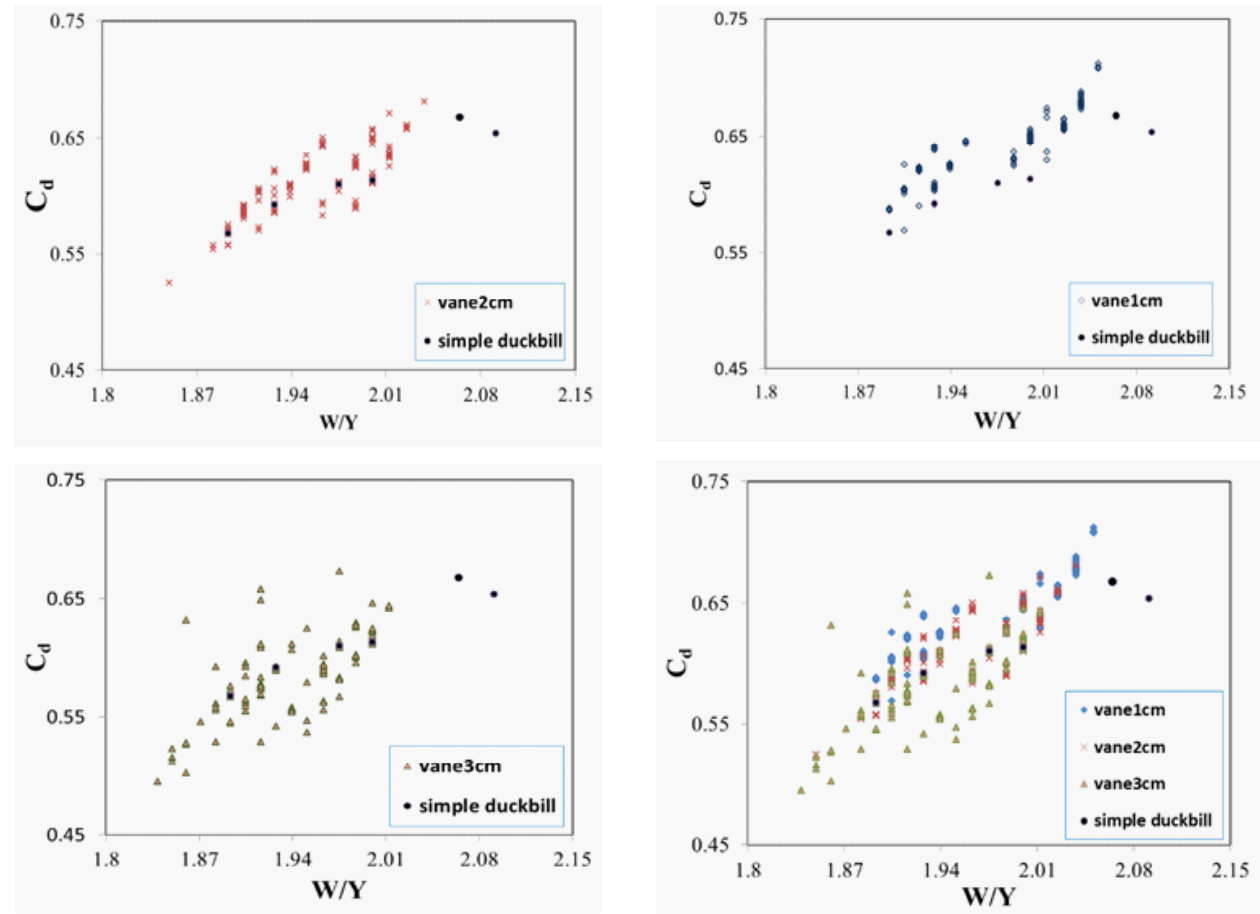

Fig13. Changes of $C d$ and $W / Y$ inmodels with guide vanes of 1, 2 and $3 \mathrm{~cm}$ width compared to simple triangular duckbill spillway 
Dimensional Analysis of Parameters Affecting the Flow Discharge Coefficient in Duckbill Spillways with Presence of Guide Vanes and Investigating Results in Laboratory Conditions

On the other hand, all of $C_{d}$ in group1 are more than the other two groups and more than simple triangular duckbill spillway and show that the W/Y ratio can be an effective factor in changing the discharge coefficient. With regard to be constant of $\mathrm{W}$, the result that was said for variations of $\mathrm{C}_{\mathrm{d}}$ to $\mathrm{L} / \mathrm{Y}$, it also applies here.

\section{Relation between Discharge Coefficient $\left(C_{d}\right)$ and $L_{v} / Y$}

In Fig. 14, the variations in the discharge coefficient $\left(\mathrm{C}_{\mathrm{d}}\right)$ versus $\mathrm{L}_{\mathrm{v}} / \mathrm{Y}$ are provided in triangular duckbill spillway for three groups and its values are compared with each other. It can be said that in all groups, increasing the ratio of $L_{v} / Y$ (decreasing water depth), $C_{d}$ increases. The discharge coefficients for group1 are greater than the other two groups, which show the greater efficiency of this width of the guide vanes. On the other hand, changing of $\mathrm{L}_{\mathrm{v}} / \mathrm{Y}$ ratio can be an effective factor in changing the flow discharge coefficient.

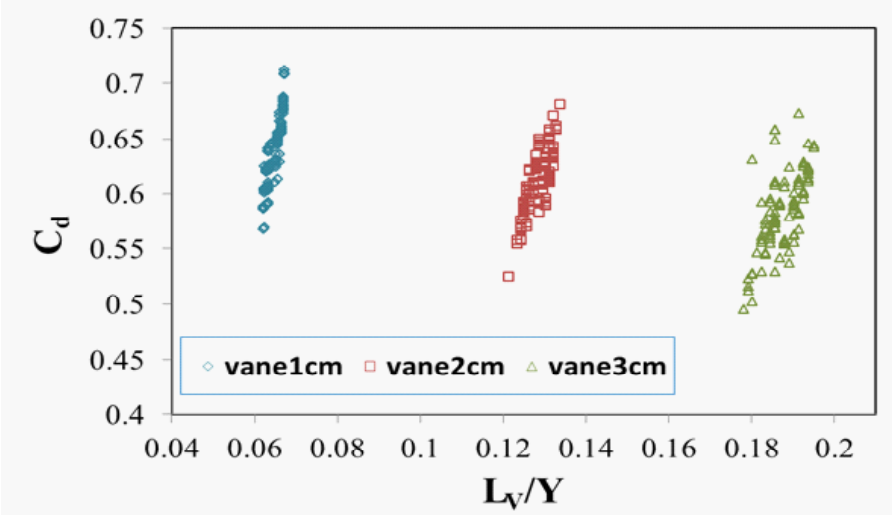

Fig14. Compared of changes in Cd and LV/Y inmodels with guide vanes of 1,2 and $3 \mathrm{~cm}$ width

The other result is the range of $\mathrm{L}_{\mathrm{v}} / \mathrm{Y}$ variations in the group models with $1 \mathrm{~cm}$ width is smaller than the other groups, because the points are clinging together. That is, in these models, the depth of water decreases with increasing flow discharge.

\section{Relation between Discharge Coefficient $\left(C_{d}\right)$ and $N$}

In Fig. 15, the variations in the discharge coefficient $\left(C_{d}\right)$ versus $N$ are provided in triangular duckbill spillway for three groups and its values are compared with each other. It can be said that for the vane with 2 and $3 \mathrm{~cm}$ width, with increasing number of vanes, the discharge coefficient has a decreasing trend. Reduce of the slope in the curve for the vane with $3 \mathrm{~cm}$ width is more than the vane with $2 \mathrm{~cm}$ width. From these diagrams it is determined that the number of vanes can affect the discharge coefficient.
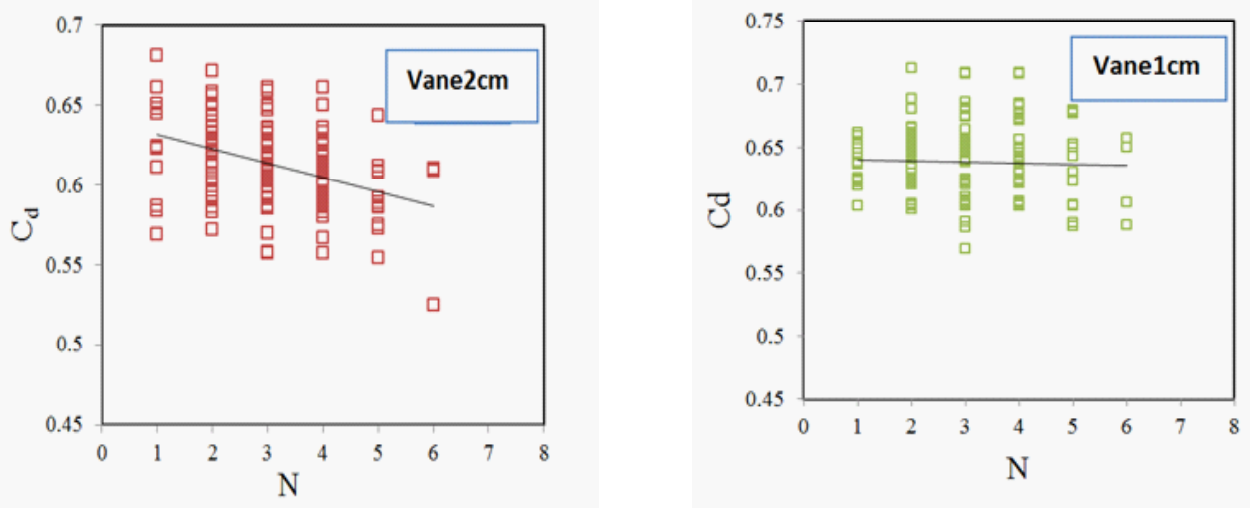

American Research Journal of Civil And Structural Engineering 
Dimensional Analysis of Parameters Affecting the Flow Discharge Coefficient in Duckbill Spillways with Presence of Guide Vanes and Investigating Results in Laboratory Conditions

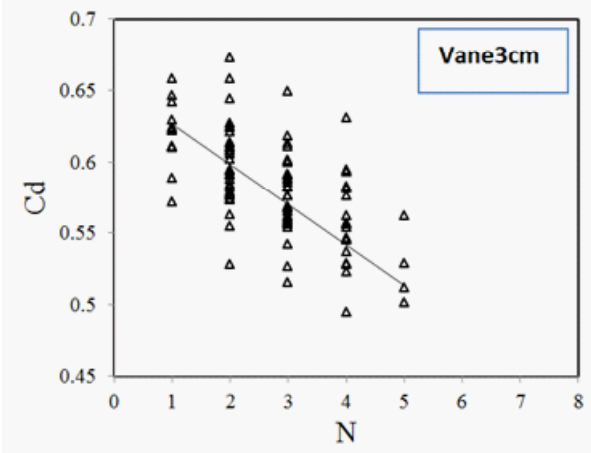

Fig15. Compared of changes in Cd and $N$ inmodels with guide vanes of 1, 2 and $3 \mathrm{~cm}$ width

\section{Relation between Discharge Coefficient (Cd) and S}

In Fig. 16, the variations in the discharge coefficient $\left(C_{d}\right)$ versus $S$ are provided in triangular duckbill spillway for three groups and its values are compared with each other. It should be noted that the numbering of horizontal axis represents the various location of deployment (S) indicated in Table 1.
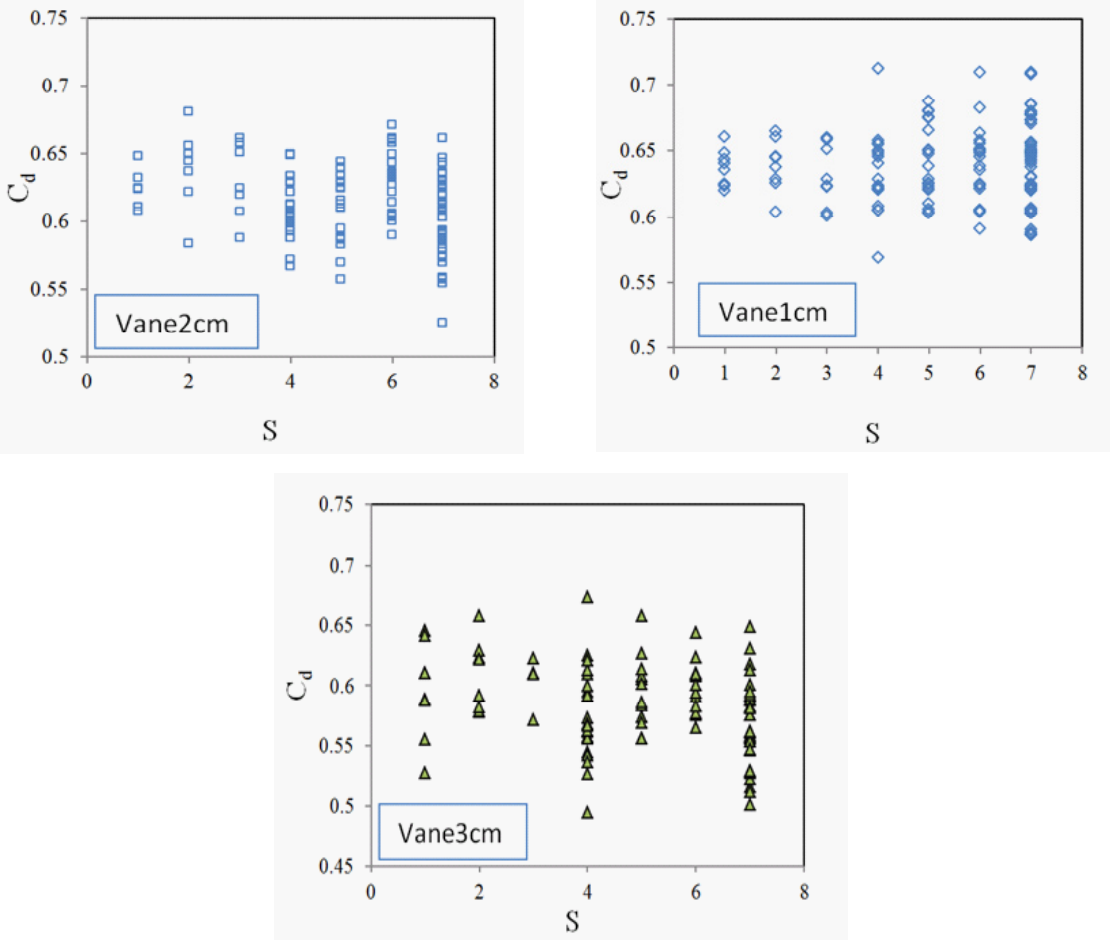

Fig16. Compared of changes in $C d$ and $S$ inmodels with guide vanes of 1,2 and $3 \mathrm{~cm}$ width

The location of deployment can affect the discharge coefficient $\left(C_{d}\right)$, since the $C_{d}$ varies in different situations. However, determining the best location of deployment is not clear from this figure.

Table1. Naming of location of guide vanes

\begin{tabular}{|c|c|c|c|c|c|c|c|}
\hline S & 1 & 2 & 3 & 4 & 5 & 6 & 7 \\
\hline Location of Deployment & aa' & $\mathrm{bb}^{\prime}$ & $\mathrm{cc}^{\prime}$ & $\mathrm{aa}^{\prime}-\mathrm{bb}^{\prime}$ & $\mathrm{aa}^{\prime}-\mathrm{cc}^{\prime}$ & $\mathrm{bb}^{\prime}-\mathrm{cc}^{\prime}$ & $\mathrm{aa}^{\prime}-\mathrm{bb}^{\prime}-\mathrm{cc}^{\prime}$ \\
\hline
\end{tabular}




\section{CONCLUSION}

- The discharge coefficient $\left(C_{d}\right)$ for straight spillway is greater than the $C_{d}$ in triangular duckbill spillway. But the scope of the changes of the discharge coefficient for triangular duckbill spillway is greater than the straight spillway, which indicates that changing the water depth, $\mathrm{C}_{\mathrm{d}}$ in triangular duckbill spillway changes more than the $C_{d}$ in straight spillway. It can be seen that in two spillways mentioned, increasing the $L / Y$ ratio, the discharge coefficient first increases and then decreases.

- The trend of changes in the discharge coefficient $\left(\mathrm{C}_{\mathrm{d}}\right)$ with the change in L/Y ratio in all three groups of vanes is the same. On the other hand, the discharge coefficients in group1 are more than the other two groups and simple triangular duckbill. It shows that the L/Y ratio can be an effective factor in changing the discharge coefficient.

- In two spillways, increasing the $\mathrm{P} / \mathrm{Y}$ ratio (decreasing water depth), the discharge coefficient $\left(\mathrm{C}_{\mathrm{d}}\right.$ ) first increases and then decreases. Flow discharge coefficients for group1 are more than the other two groups and more than simple triangular duckbill spillway. It shows that the $\mathrm{P} / \mathrm{Y}$ ratio can be an effective factor in changing the discharge coefficient.

- In all models, the discharge coefficient $\left(\mathrm{C}_{\mathrm{d}}\right)$ decreases with increasing Froude number (Fr). In this case too, flow discharge coefficients for group 1 are more than the other two groups and more than simple triangular duckbill spillway. It shows that the Froude number (Fr) can be an effective factor in changing the discharge coefficient.

- In two spillways, increasing the $W / Y$ ratio, the discharge coefficient $\left(C_{d}\right)$ first increases and then decreases. Flow discharge coefficients for group1 are more than the other two groups and more than simple triangular duckbill spillway. It shows that the $\mathrm{W} / \mathrm{Y}$ ratio can be an effective factor in changing the discharge coefficient.

- In all groups, increasing the $\mathrm{L}_{\mathrm{v}} / \mathrm{Y}$ ratio (decreasing water depth), the discharge coefficient $\left(\mathrm{C}_{\mathrm{d}}\right)$ increases. The flow discharge coefficients for group 1 are more than the other two groups, which shows that the more efficiency of this width of the vane (vane with $1 \mathrm{~cm}$ width). It also shows that the $\mathrm{L}_{\mathrm{V}} / \mathrm{Y}$ ratio can be an effective factor in changing the discharge coefficient $\left(\mathrm{C}_{\mathrm{d}}\right)$.

- For vanes with 2 and $3 \mathrm{~cm}$ width, with increasing number of vanes, the discharge coefficient has a decreasing trend. Reduce of the slope in the curve for the vane with $3 \mathrm{~cm}$ width is more than the vane with $2 \mathrm{~cm}$ width. Therefore, the number of vanes can affect the flow discharge coefficient.

- The location of the deployment of vanes can affect the discharge coefficient $\left(C_{d}\right)$, since the discharge coefficient varies in different situations.

\section{NOMENCLAUTURE}

$C_{d}$ Flow discharge coefficient (-);

Fr The Froude number (-);

$g$ Gravity acceleration $\left(\mathrm{m} / \mathrm{s}^{2}\right)$;

$H$ Static head water $(\mathrm{m})$;

$H_{t}$ Total head water $(\mathrm{m})$;

$H_{V}$ Dynamic head water $(\mathrm{m})$;

$L$ Effective length of the spillway (m);

$L_{v}$ Width of the vane $(\mathrm{m})$;

American Research Journal of Civil And Structural Engineering 
Dimensional Analysis of Parameters Affecting the Flow Discharge Coefficient in Duckbill Spillways with Presence of Guide Vanes and Investigating Results in Laboratory Conditions

$N$ Number of guide vane (-);

$n$ The number of cycles of spillway (-);

$P$ Spillway height (m);

$Q$ Flow discharge $\left(\mathrm{m}^{3} / \mathrm{s}\right)$;

Re The Reynolds number (-);

$S$ Location of deployment of guide vane (-);

$S_{0}$ Longitudinal slope of the channel (\%);

$V_{o}$ Average upstream velocity $(\mathrm{m} / \mathrm{s})$;

$W$ Channel width (m);

We The Weber number (-);

$Y$ Upstream water depth (m);

$\alpha$ Apex angle (degree);

$\theta$ Wall angle of located vane (degree);

$\rho$ Density of fluid $\left(\mathrm{kg} / \mathrm{m}^{3}\right)$;

$\mu$ Dynamics viscosity of fluid (N. S/m²);

$\sigma$ Fluid surface tension $(\mathrm{N} / \mathrm{m})$

\section{REFERENCES}

1. Ansari, A. 2009. Effective hydraulic parameters in improving performance of oblique weir, Master of civil engineering thesis, Isfahan University of Technology.

2. Hay, N. and G. Taylor. 1970. Performance and design of labyrinth weirs. Journal of Hydraulic Engineering. ASCE 96(11): 2337-2357.

3. Samani, H. 1997. Design of Hadraulic Structures.

4. Hay, N. and G. Taylor. 1972. Performance and design of labyrinth weirs. Journal of Hydraulic Engineering. ASCE 96(4): 708-711.

5. Ghare, A. D. , V. A. Mhaisalkar and P. D. Porey. 2008. An approach to optimal design of trapezoidal labyrinth weirs. Journal of World Applied Science. 3(6):934-938.

6. Tullis J. P. Amanian N. and Waldron D. 1995. Design of Labyrinth Spillways. Journal of Hydraulic Engineering. ASCE 121(3): 247-255.

Citation: Seyedeh Zahra Hosseini-Teshnizi, Manouchehr Heidarpour, Seyed Saeid Eslamian, Kaveh Ostad-Ali-Askari, "Dimensional Analysis of Parameters Affecting the Flow Discharge Coefficient in Duckbill Spillways with Presence of Guide Vanes and Investigating Results in Laboratory Conditions", American Research Journal of Civil and Structural Engineering, vol 2, no. 1, pp. 1-13.

Copyright (c) Seyedeh Zahra Hosseini-Teshnizi, Manouchehr Heidarpour, Seyed Saeid Eslamian, Kaveh Ostad-Ali-Askari, This is an open access article distributed under the Creative Commons Attribution License, which permits unrestricted use, distribution, and reproduction in any medium, provided the original work is properly cited. 